Biomass Effects and Selenium

\section{Accumulation in Sprouts of Three Vegetable Species Grown in Selenium-enriched Conditions}

\author{
Sara Arscott \\ Department of Nutritional Sciences, University of Wisconsin-Madison, 1415 \\ Linden Drive, Madison, WI 53706
}

Irwin Goldman ${ }^{1}$

Department of Horticulture, University of Wisconsin-Madison, 1575 Linden

Drive, Madison, WI 53706

Additional index words. selenium, vegetable sprouts, biofortification

\begin{abstract}
Foods that can aid in prevention of disease are of increasing interest. Some vegetables experimentally enriched with selenium (Se) accumulate selenium as Se-methylselenocysteine (MeSeCys), a non-protein amino acid implicated with superior chemopreventive properties. The effects of increasing concentrations of Se on the gain in biomass (GIB) and total Se concentration of broccoli (Brassica oleracea), mung bean (Vigna radiata), and onion (Allium cepa 'Red creole') sprouts were evaluated against sulfur (S) as control. Trial 1 included treatments of selenate-Se and sulfate-S at levels of $127 \mu \mathrm{mol} \cdot \mathrm{L}^{-1}$ and $1270 \mu \mathrm{mol} \cdot \mathrm{L}^{-1}$. Trial 2 used additional treatments of $635 \mu \mathrm{mol} \cdot \mathrm{L}^{-1}$ for broccoli and mung beans and $12,700 \mu \mathrm{mol} \cdot \mathrm{L}^{-1}$ for onion. Sprouts were harvested at 3 and 5 days for broccoli and mung bean and at 5 and 7 days for onion. Broccoli was the most sensitive to Se, showing $\approx 45 \%$ GIB reduction at $635 \mu$ M Se. Mung bean GIB was $23 \%$ lower at 1,270 $\mu \mathrm{M}$ Se and onion GIB showed a small $16 \%$ reduction at $12,700 \mu \mathrm{M} \mathrm{Se}$, suggesting high Se tolerance. These data clearly demonstrated species variation in tolerance to and uptake of Se during sprout production. The lowest treatment level, $127 \mu \mathrm{M}$ selenate-Se, resulted in Se concentrations that exceeded the level desirable for fresh sprout consumption, suggesting that Se-biofortified sprout production for fresh consumption could be easily accomplished with little effect on growth rate or yield. Chemical name used: selenate $\left(\mathrm{SeO}_{4}{ }^{2-}\right)$ sulfate $\left(\mathrm{SO}_{4}{ }^{2-}\right)$.
\end{abstract}

Vegetables from the Brassicaceae and Alliaceae families are rich in phytochemicals known as glucosinolates and organosulfur compounds, respectively, that may possess specific anticarcinogenic effects (Fahey et al., 1997). Vegetable crops in these families synthesize these compounds after S uptake. However, Se can enter plant roots using the same S-transport system and result in the formation of organoselenium compounds, in which an Se atom replaces a $\mathrm{S}$ atom in an organic compound (Terry et al., 2000). Although Se uptake by plants is inadvertent, it could be serendipitous because a number of organoselenium compounds exhibit the potential to inhibit the growth of certain types of cancer cells and aid in chemotherapy treatments (Nilsonne et al., 2006; Tsavachidou et al., 2009). Unfortunately, the detrimental effects of Se on plant growth are well documented, rendering the production of Se-enriched plant tissues a challenge. On the positive side, however, species

Received for publication 7 Feb. 2012. Accepted for publication 28 Feb. 2012.

We thank Professor Kirk Parkin for his guidance, support, and technical assistance.

${ }^{1}$ To whom reprint requests should be addressed; e-maililgoldma@wisc.edu. in the genera Brassica and Allium accumulate Se as MeSeCys, a non-protein amino acid implicated with superior chemopreventive effects compared with other organoselenium compounds (Ellis and Salt, 2003).

Plants that can accumulate Se greater than 100 and less than $1000 \mu \mathrm{g} \cdot \mathrm{g}^{-1}$ Se dry weight have been termed secondary Se accumulators and include species of Brassica and Allium (Banuelos, 2002; Ellis and Salt, 2003; Terry et al., 2000). This level of Se accumulation tends to be associated with growth reduction in these plants. Lefsrud et al. (2006) found that when kale (Brassica oleracea vars. acephala, viridis) leaves averaged $1056 \mu \mathrm{g} \cdot \mathrm{g}^{-1}$ Se dry weight, they had a $27 \%$ reduction in fresh plant biomass compared with plants grown with no Se. Barak and Goldman (1997) demonstrated that when onion plants (Allium cepa var. Stuttgarter) accumulated content of Se in the plants did not significantly increase as a result of limited growth. Total fresh weight of rapid-cycling Brassica oleracea showed $42 \%$ reduction when leaf accumulation of Se reached $1900 \mu \mathrm{g} \cdot \mathrm{g}^{-1} \mathrm{Se}$, dry weight, compared with plants grown without Se (Kopsell and Randle, 1999). Therefore, although high Se concentrations in growing medium can lead to high Se more than $300 \mu \mathrm{g} \cdot \mathrm{g}^{-1}$ Se dry weight, the concentration in plant tissues, the optimal production of plants in terms of both $\mathrm{Se}$ concentration and biomass must take into consideration the levels of Se that are toxic to specific plants.

The enrichment of vegetables with $\mathrm{Se}$ requires the addition of $\mathrm{Se}$ to the growing environment of the plants and this has the potential for environmental pollution. Indeed, a large proportion of Se research has been focused on finding ways to remediate naturally occurring Se-laden soils for the safe production of food and grazing of animals (Banuelos et al., 2002). Additionally, human activities such as agriculture, coal burning, and metal and phosphorus mining have contributed to Se contamination of the environment (Lemly, 2004). Therefore, a closed system is desirable for producing Se-enriched foods.

Sprouted vegetable seeds, or sprouts, are germinated in a closed system that is easy and ideal for Se-enrichment. Compared with mature broccoli plants, the sprouts of broccoli have been reported to contain 10 to 100 times higher glucosinolate levels, important precursors of sulforaphane, a potent inducer of Phase II detoxification enzymes, and chemoprotective in chemically induced rodent tumors (Fahey et al., 1997). Sprouts of 28 different species of vegetables were grown in the presence of $5.0 \mu \mathrm{g} \cdot \mathrm{mL}^{-1}$ to 10.0 $\mu \mathrm{g} \cdot \mathrm{mL}^{-1}$ of Se as sodium selenite and analyzed for their content of Se as well as the proportion of inorganic and organic forms of Se (Sugihara et al., 2004). The Se concentration ranged from 7.8 to $46.3 \mu \mathrm{g} \cdot \mathrm{g}^{-1} \mathrm{Se}$, fresh weight or 1.5 to 4.7 times higher than the $\mathrm{Se}$ in the environment, for soybean (Glycine max) and parsley (Petroselinium crispum), respectively. Abdulah et al. (2009) showed that Se-enriched broccoli sprouts (Brassica oleracea) were superior to standard broccoli in inhibiting cell proliferation, decreasing prostate-specific antigen secretion, and inducing apoptosis of prostate cancer cells. Their work suggested that Se-enriched broccoli sprouts could be a vehicle for Se supplementation in prostate cancer therapies. The aim of the current investigation was to develop Se-biofortified sprouts in hydroponic culture and compare the growth of three different species under high-Se cultivation.

\section{Materials and Methods}

Two experiments were performed in which seeds of three vegetable species, broccoli (Brassica oleracea), onion (Allium cepa), and mung bean (Vigna radiata), were germinated until they reached an "edible sprout" size. This size is dependent on the species and ranged in length from $\approx 2$ to $4 \mathrm{~cm}$ for onion, 4 to $6 \mathrm{~cm}$ for broccoli, and 5 to $10 \mathrm{~cm}$ for mung bean. Trial 1 was begun on 11 Nov. 2004 and Trial 2 was begun on 18 Feb. 2005. Seeds of broccoli, mung bean, and onion (var. red creole) were obtained from Johnny's Selected Seeds (Winslow, ME). All of the equipment was sanitized with $5 \%$ household bleach and rinsed with deionized water. Before 
germination, the seeds were first sanitized in $2 \% \mathrm{CaClO}_{2}$ for $20 \mathrm{~min}$ and triple-washed with deionized water. The seed samples ( $20 \mathrm{~g}$ broccoli, $10 \mathrm{~g}$ mung bean, $15 \mathrm{~g}$ onion) were then soaked for $10 \mathrm{~h}$ in their respective treatment solutions $(100 \mathrm{~mL})$. The seed mass for each species was chosen to give approximate similar seed volumes.

The treatment solutions for both trials included deionized water, $\mathrm{Na}_{2} \mathrm{SeO}_{4}$-Se, or $\mathrm{Na}_{2} \mathrm{SO}_{4}$-S. Sulfur was chosen as a positive control because it is a plant nutrient and $\mathrm{Se}$ uptake follows $\mathrm{S}$ accumulation pathways. Additionally, by comparing salts of Se and $\mathrm{S}$, conclusions may be drawn about the plasmolytic effect of high salt concentrations on growth. Trial 1 included treatments of $\mathrm{SeO}_{4}{ }^{2-}-\mathrm{Se}$ and $\mathrm{SO}_{4}{ }^{2-}-\mathrm{S}$ at levels of 127 $\mu \mathrm{mol} \cdot \mathrm{L}^{-1}(127 \mu \mathrm{M}$ Se and $127 \mu \mathrm{M} \mathrm{S})$ and $1270 \mu \mathrm{mol} \cdot \mathrm{L}^{-1}(1270 \mu \mathrm{M}$ Se and $1270 \mu \mathrm{M} \mathrm{S})$. Trial 2 used those same treatments and additional treatments of $\mathrm{SeO}_{4}{ }^{2-}-\mathrm{Se}$ and $\mathrm{SO}_{4}{ }^{2-}-\mathrm{S}$ at an intermediate level of $635 \mu \mathrm{mol} \cdot \mathrm{L}^{-1}$ (635 $\mu \mathrm{M}$ Se and $635 \mu \mathrm{M} \mathrm{S}$ ) for broccoli and mung beans and $12,700 \mu \mathrm{mol} \cdot \mathrm{L}^{-1}(12,700 \mu \mathrm{M} \mathrm{Se}$ and $12,700 \mu \mathrm{M} \mathrm{S}$ ) for onion.

After soaking, the treatments were drained and the seeds sown into black plastic $12.7 \mathrm{~cm} \times 12.7-\mathrm{cm}$ sprouting boxes (Hummert Int., Earth City, MO) with perforated bottoms lined with autoclaved absorbent jute grass-based felt pads (Baby blanket; Kelpman Products, North Vancouver, British Columbia, Canada). Three replicates of each treatment for each harvest date were arranged in a completely randomized design into $25.4 \mathrm{~cm} \times 50.8-\mathrm{cm}$ black plastic drip trays, sealed with a polyvinylindene chloride film (Saran Wrap; SC Johnson \& Sons Inc., Racine, WI) to prevent evaporation of water, and covered with an inverted drip tray for darkness. Both experiments took place on a laboratory bench and germination was accomplished at an average temperature of 22$25^{\circ} \mathrm{C}$ for the duration of the cultivation periods. The seeds received $100-\mathrm{mL}$ treatment applications in the following fashion: Trial 1, Days 0,1 , and 3; and Trial 2, Days 0, 1, 2, and 4 for all plus Day 6 for onion only. The treatment was poured over the sprouting seeds and allowed to drain out the bottom of the sprouting box, similar to industrial sprouting methods whereby specific amounts of water are sprayed into large bins of sprouting seeds and allowed to drain through gravity.
Broccoli and mung bean samples were harvested on Days 3 and 5. As a result of their slower growth, onion samples were harvested on Days 5 and 7. The sprouts were triplewashed with $800 \mathrm{~mL}$ deionized water, put into plastic bags, and frozen at $-80{ }^{\circ} \mathrm{C}$. The samples were then lyophilized and transferred to plastic 50-mL tubes. Glass beads were added to the tubes, and grinding was accomplished by 5-min vigorous shaking with a modified industrial paint shaker (Model C1; Fleming Gray, Cambridge, Ontario, Canada). Comparisons between species were made based on percent change in biomass, referred to as GIB, which was calculated as [fresh weight gain in mass $(\mathrm{g})$ - initial seed weight (g)/initial seed weight $(\mathrm{g})$ ]. Plant tissue was analyzed for elemental Se by inductively coupled plasma mass spectrometry with a VG PlasmaQuad Model PQ2Turbo Plus (VG Elemental; Isoprime, Cheadle, U.K.) at the University of Wisconsin Soil and Plant Analysis Laboratory. The method used was an adaptation of the U.S. Environmental Protection Agency (USEPA) method 3050B (USEPA, 2012). The detection limit was $0.4 \mu \mathrm{g} \cdot \mathrm{g}^{-1} \mathrm{Se}$, dry weight. Only the Se and the water-treated samples were analyzed for Se concentration in both trials. Data were analyzed by analysis of variance using the ProcMixed procedure of SAS (Statistical Analysis Systems, Cary, NC).

\section{Results and Discussion}

Effect of sulfur and selenium treatments on biomass. The main effects of species, treatment, and harvest date in both Trials 1 and 2 were highly significant for GIB (Table 1 ). Averaged over treatments and days, broccoli consistently gained the most biomass. In Trials 1 and 2, broccoli gained 21\% and 53\% more biomass than mung bean and $40 \%$ and $68 \%$ more biomass than onion, respectively. The GIB of broccoli averaged over treatments and days was 36\% greater in Trial 2 than in Trial 1. Mung bean and onion gained $8 \%$ and $17 \%$ less biomass than in Trial 1 , respectively. The increased GIB of broccoli in the second trial may have been the result of the increased number of treatment applications. However, this does not explain the decreased GIB of mung bean and onion.

The $127-\mu \mathrm{M}$ S treatment was associated with the largest GIB averaged over species and harvest dates in both trials. The $1270-\mu \mathrm{M}$ Se treatment was consistently associated with the smallest GIB, $28 \%$ and $34 \%$ reductions compared with the $127-\mu \mathrm{M} \mathrm{S}$ treatment for Trials 1 and 2, respectively. The magnitude of treatment effects on GIB differed between and among species. Because of these different responses, the species were subsequently analyzed separately.

In the separate analysis, the treatment $x$ harvest date interaction was significant for all species in Trial 1 and for broccoli in Trial 2 (Table 2) and, although attributable primarily to change in magnitude of GIB response, was also partially the result of changes in rank. The main effect of harvest date was, predictably, to cause a GIB from the first to the second harvest day for all of the treatments within each species (Fig. 1). As a result of the significance of the interaction, the harvest dates were analyzed separately. The remaining analysis will focus on the main effects of treatment in each of the species on the different harvest days.

In broccoli, the $127-\mu \mathrm{M} \mathrm{S}$ treatment was associated with the greatest GIB on both harvest dates, and the ranking of the other treatments was similar between harvest dates and over the two trials (Figs. 1 and 2). The smallest GIB was associated with the $1270-\mu \mathrm{M}$ Se treatment, $34 \%$ and $46 \%$ reductions compared with the water control for Trials 1 and 2, respectively, and significant only on the second date. In Trial 2, the $635-\mu \mathrm{M}$ Se-treated broccoli sprouts were associated with similar GIB reductions as the $1270-\mu \mathrm{M}$ Se-treated sprouts. These results demonstrate that broccoli sprout growth may be significantly reduced at levels of $635 \mu \mathrm{M}$ Se but not $127 \mu \mathrm{M}$ Se as sodium selenate.

In mung bean on the second harvest date, the $1270-\mu \mathrm{M}$ Se treatment was also associated with the smallest GIB, $30 \%$ and $17 \%$ reductions compared with the water control for Trials 1 and 2, respectively. The lack of growth reduction associated with the $635-\mu \mathrm{M}$ Setreated mung beans sprouts suggests they may be more tolerant to Se than broccoli sprouts.

Onions treated with $1270 \mu \mathrm{M}$ Se were associated with a small but significant $12 \%$ reduction in GIB compared with the water control for the second harvest date in Trial 1. In Trial 2, although onion showed no overall difference of GIB between the two harvest dates, the onions treated with $1270-\mu \mathrm{M}$ Se

Table 1. Results from overall analysis of variance ${ }^{\mathrm{z}}$ for gain in biomass and elemental tissue selenium concentration of vegetable sprouts using analysis of variance in the PROCMIXED procedure of SAS.

\begin{tabular}{|c|c|c|c|c|c|c|c|c|}
\hline \multirow[b]{3}{*}{ Source of variation } & \multicolumn{4}{|c|}{ Gain in biomass $\left(\mathrm{g} \cdot \mathrm{g}^{-1}\right)$} & \multicolumn{4}{|c|}{ Selenium $\left(\mu \mathrm{g} \cdot \mathrm{g}^{-1} \mathrm{Se}\right)$} \\
\hline & \multicolumn{2}{|c|}{ Trial 1} & \multicolumn{2}{|c|}{ Trial 2} & \multicolumn{2}{|c|}{ Trial 1} & \multicolumn{2}{|c|}{ Trial 2} \\
\hline & $\mathrm{df}$ & F value ${ }^{y}$ & $\mathrm{df}$ & F value ${ }^{y}$ & df & F value ${ }^{y}$ & $\mathrm{df}$ & F value $^{\mathrm{y}}$ \\
\hline Species & 2 & $278.9 * * *$ & 2 & $586.2 * * *$ & 2 & $243.4 * * *$ & 2 & $15.3 * * *$ \\
\hline Treatment & 4 & $39.6 * * *$ & 4 & $21.9 * * *$ & 2 & $5935.8 * * *$ & 1 & $145.5 * * *$ \\
\hline Day & 1 & $393.6 * * *$ & 1 & $372.4 * * *$ & 1 & $111.4 * * *$ & 1 & $44.6 * * *$ \\
\hline Species*treatment & 8 & $12.1 * * *$ & 8 & $13.4 * * *$ & 4 & $230.6 * * *$ & 2 & NS \\
\hline Species*day & 2 & $45.4 * * *$ & 2 & $214.6 * * *$ & 2 & $17.8 * * *$ & 2 & $6.6^{*}$ \\
\hline Treatment*day & 4 & $9.3 * * *$ & 4 & $11.1 * * *$ & 2 & $49.5 * * *$ & 1 & $11.5^{*}$ \\
\hline Species*treatment*day & 8 & NS & 8 & $9.1^{* * *}$ & 4 & $16.2 * * *$ & - & NS \\
\hline
\end{tabular}

${ }^{\mathrm{z}}$ Only selenium-treated samples common to all species included in analysis.

y***, $* *, *$, NS $=P<0.0001, P<0.001, P<0.05$, nonsignificant, respectively. 
Table 2. Results from analysis of variance for gain in biomass and elemental tissue selenium concentration by species using analysis of variance in the PROCMIXED procedure of SAS.

\begin{tabular}{|c|c|c|c|c|c|c|c|c|}
\hline \multirow{2}{*}{ Source of variation } & \multicolumn{4}{|c|}{ GIB $\left(g \cdot g^{-1}\right)$} & \multicolumn{4}{|c|}{$[\mathrm{Se}]\left(\mu \mathrm{g} \cdot \mathrm{g}^{-1}\right)$} \\
\hline & \multicolumn{2}{|c|}{ Trial 1} & \multicolumn{2}{|c|}{ Trial 2} & \multicolumn{2}{|c|}{ Trial 1} & \multicolumn{2}{|c|}{ Trial 2} \\
\hline \multicolumn{9}{|l|}{ Broccoli } \\
\hline Day & 1 & $141.89 * * *$ & 1 & $391.5^{* * *}$ & 1 & $138.7 * * *$ & 1 & $69.4 * * *$ \\
\hline Treatment*day & 4 & $3.22 *$ & 6 & $16.4 * * *$ & 1 & $56.6^{* *}$ & 2 & $5.2 *$ \\
\hline \multicolumn{9}{|l|}{ Mung bean } \\
\hline Treatment & 4 & $48.26^{* * *}$ & 6 & $9.1 * * *$ & 1 & $1378.9 * * *$ & 2 & $20.5^{* *}$ \\
\hline \multicolumn{9}{|l|}{ Onion } \\
\hline Treatment & 4 & $14.09 * * *$ & 6 & $7.4 * * *$ & 1 & $4482.3 * * *$ & 2 & $929.1 * * *$ \\
\hline Day & 1 & $553.63 * * *$ & 1 & NS & 1 & $49.5 * *$ & 1 & $109.5^{* * *}$ \\
\hline Treatment*day & 4 & $3.37 *$ & 6 & NS & 1 & $48.5^{* *}$ & 2 & $75.5^{* * *}$ \\
\hline
\end{tabular}

z***,**, *, NS $=P<0.0001, P<0.001, P<0.05$, nonsignificant, respectively.

$\mathrm{GIB}=$ gain in biomass; $[\mathrm{Se}]=$ elemental selenium.

NS = nonsignificant.

\section{Broccoli}

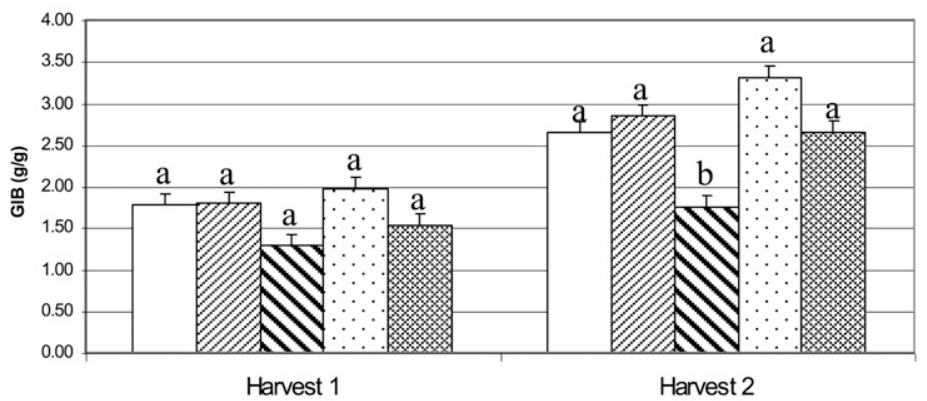

Mung Bean

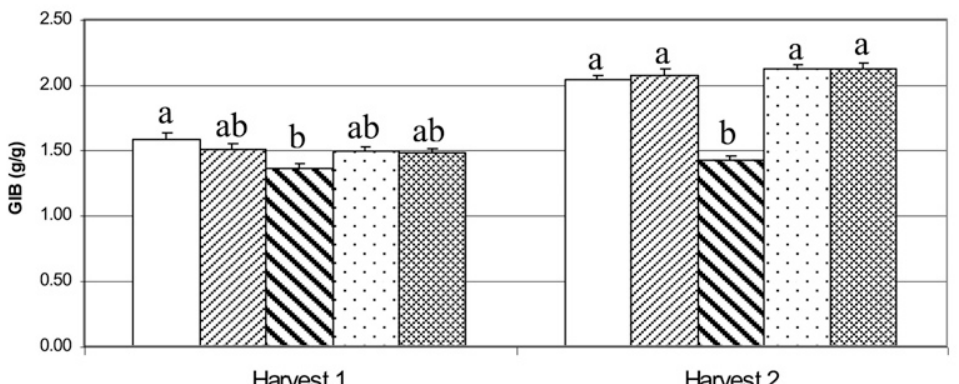

$\square$ Water
$\square 127 \mu \mathrm{M} \mathrm{Se}$
$\mathbb{1} 1270 \mu \mathrm{M} \mathrm{Se}$
$\square 127 \mu \mathrm{MS}$
$1270 \mu \mathrm{MS}$

Onion

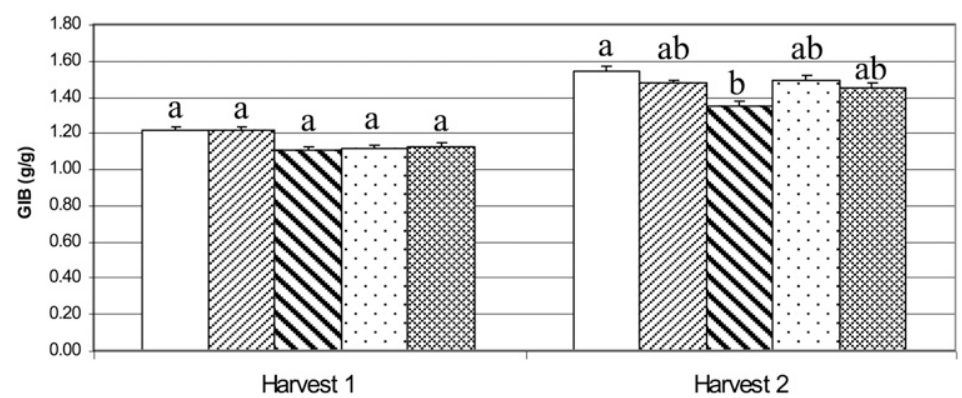

Fig. 1. Trial 1: Gain in biomass (GIB) of broccoli, mung bean, and onion sprouts for 2 harvest dates. Each bar represents the average and SE of three samples. Means on the same day with the same letter are not significantly different $(P<0.001)$. Harvest $1=$ Day 3 for broccoli and mung bean, Day 5 for onion; Harvest 2 = Day 5 for broccoli and mung bean, Day 7 for onion. GIB $=\mathrm{g}$ gain in biomass $/ \mathrm{g}$ of initial sample.

treatment showed no reduced GIB. Onions treated with $12,700 \mu \mathrm{M}$ Se were consistently associated with the smallest GIB, a $16 \%$ reduction compared with the water control on the second harvest date. This suggests that onion is more tolerant to Se than broccoli and mung bean. However, it is difficult to draw definitive conclusions from these data because onion did not gain in biomass between harvest dates in any of the treatment groups. Additionally, the mass of the imbibed seed of onion is much greater than the mass of 

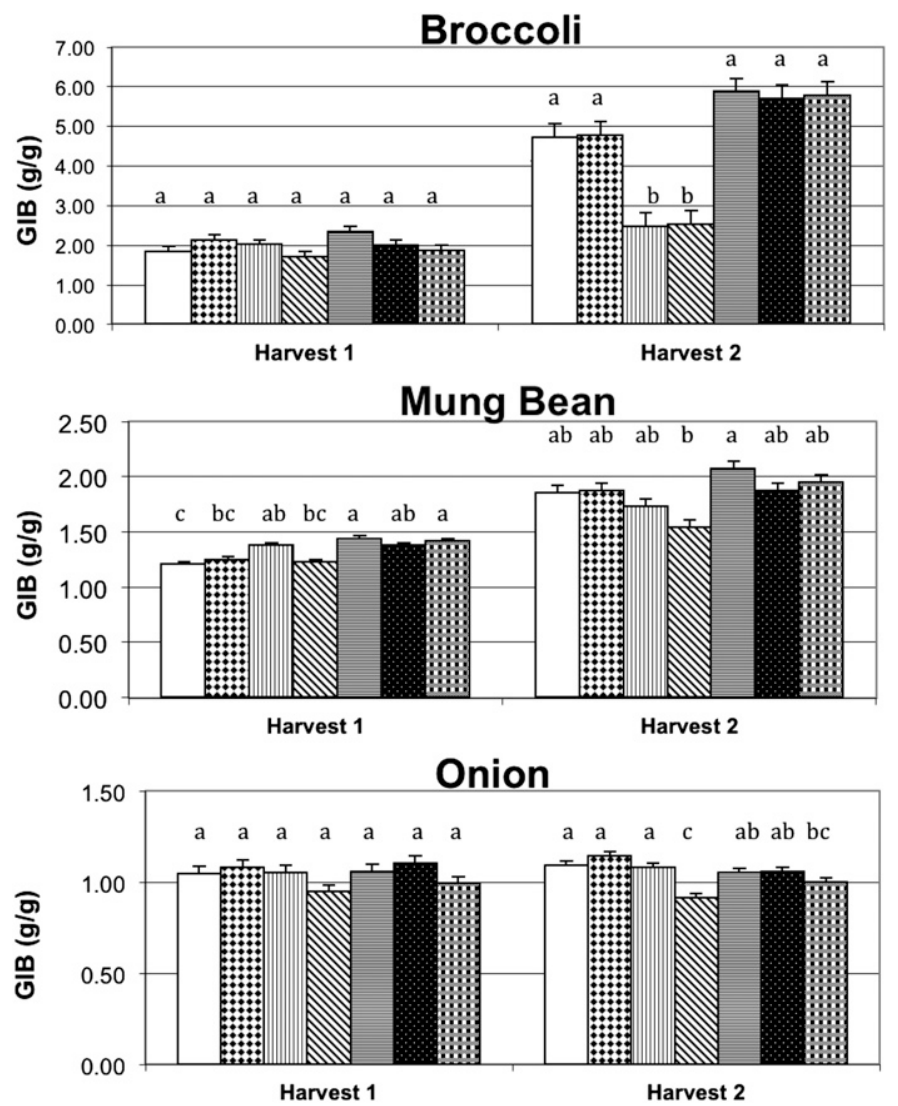

Fig. 2. Trial 2: Gain in biomass (GIB) of broccoli, mung bean, and onion sprouts for 2 harvest days. Bars, from left to right, represent the water control, $127 \mu \mathrm{m} \mathrm{Se}, 635 \mu \mathrm{m} \mathrm{Se}, 1270 \mu \mathrm{m} \mathrm{Se}, 127 \mu \mathrm{m} \mathrm{S}, 635 \mu \mathrm{m} \mathrm{S}$, and $1270 \mu \mathrm{m} \mathrm{S}$ treatments for broccoli and mung bean. For onion, bars from left to right represent the water control, $127 \mu \mathrm{m} \mathrm{Se}, 1,270 \mu \mathrm{m} \mathrm{Se}, 12,700 \mu \mathrm{m} \mathrm{Se}, 127 \mu \mathrm{m} \mathrm{S}, 1,270 \mu \mathrm{m} \mathrm{S}$, and 12,700 $\mu \mathrm{m} \mathrm{S}$ treatments. Each bar represents the average and SE of three samples. Means on the same day with the same letter are not significantly different $(P<0.001)$. Harvest $1=$ Day 3 for broccoli and mung bean, Day 5 for onion; Harvest $2=$ Day 5 for broccoli and mung bean, Day 7 for onion. GIB $=\mathrm{g}$ gain in biomass/g of initial sample. $\mathrm{Se}=$ selenium.

the elongating root-hypocotyl, resulting in very small changes in the mass of the sprouts overall as they grow. Other possible factors include decreased viability of the onion seed as a result of aging of the seed between trials or some unidentified suboptimal environmental conditions.

There was a nonsignificant trend toward greater GIB of broccoli at the $127-\mu \mathrm{M} \mathrm{S}$ treatment level compared with water in both trials, suggesting that $\mathrm{S}$ may give broccoli a growth advantage at this stage of development. The GIB associated with the $1270-\mu \mathrm{M}$ Se-treated sprouts of all three species did not significantly differ between harvest dates, suggesting growth inhibition at this Se concentration. Additionally, in broccoli and mung bean, the high GIB responses associated with the $1270-\mu \mathrm{M}$ S treatment suggest that the reductions in growth associated with the $1270-\mu \mathrm{M}$ Se treatments are likely not the result of the plasmolytic effect of the high salt concentration, but rather the toxic effect of Se.

In general, none of the species in the current study showed reduced growth at $127 \mu \mathrm{M}$ Se $\left(10 \mathrm{mg} \cdot \mathrm{L}^{-1}\right.$ selenate-Se) and all had reduced growth at greater than $1270 \mu \mathrm{M} \mathrm{Se}$ (100 $\mathrm{mg} \cdot \mathrm{L}^{-1}$ selenate-Se). Lintschinger et al. (2000) reported slight growth reductions with wheat (Triticum aestivum) and alfalfa (Medicago sativa) seeds but no reduction in germination rate at $50 \mathrm{mg} \cdot \mathrm{L}^{-1}$ selenate-Se and reduced but vigorous growth up to 200 $\mathrm{mg} \cdot \mathrm{L}^{-1}$ selenate-Se. Sunflower (Helianthus annuus) seeds showed very high resistance to the toxic effects of Se by continuing to grow in the presence of $800 \mathrm{mg} \cdot \mathrm{L}^{-1}$ selenate-Se (Lintschinger et al., 2000). Ten percent yield reduction was reported for wheat sprouts in the presence of $15 \mathrm{mg} \cdot \mathrm{L}^{-1}$ selenate-Se, whereas germination was not inhibited at levels of 152 $\mathrm{mg} \cdot \mathrm{L}^{-1}$ (Banuelos et al., 1997). Sugihara et al. (2004) reported that a treatment of $10 \mathrm{mg} \cdot \mathrm{L}^{-1}$ selenite-Se or selenate-Se applied to Kaiware daikon sprouts significantly inhibited growth. Germination conditions, however, such as temperature, seed soaking method, and surface area of solution contact can all affect hydration level in seeds and thus germination rate and mass (Obroucheva and Antipova, 1997) as well as Se uptake.

Studies with mature plants indicate that growth reductions occur at much lower $\mathrm{Se}$ concentrations than were used in the present study. The fresh weight of 2-month-old kale leaves was reduced $27 \%$ at $3.5 \mathrm{mg} \cdot \mathrm{L}^{-1}$ selenate-Se compared with $0 \mathrm{mg} \cdot \mathrm{L}^{-1} \mathrm{Se}$ (Lefsrud et al., 2006). Barak and Goldman
(1997) demonstrated that onions grown at Se concentrations greater than $2 \mathrm{mg} \cdot \mathrm{L}^{-1}$ selenateSe did not increase in Se content as a result of growth limits. Rapid-cycling Brassica oleracea plants showed $47 \%$ decreased stem fresh weight at $2.5 \mathrm{mg} \cdot \mathrm{L}^{-1}$ selenate-Se (Lemly, 2004).

In conclusion, the GIB of broccoli, onion, and mung bean responded differently to the $\mathrm{Se}$ and $\mathrm{S}$ treatments. Anatomical differences between monocots (onion) and dicots (broccoli and mung bean), differences in organ size and proportions, and genetic differences in metabolism may influence Se uptake and growth. Broccoli appeared to be the most sensitive to $\mathrm{Se}$, showing $\approx 45 \%$ GIB reduction at a level of $635 \mu \mathrm{M}$ Se. Mung bean GIB was reduced on average $23 \%$ at a level of $1,270 \mu \mathrm{M} \mathrm{Se}$ and onion GIB showed only a small $16 \%$ reduction at $12,700 \mu \mathrm{M}$ Se, suggesting that onion sprouts may be very tolerant to Se. However, longer cultivation periods may help to clarify the effects of the various $S e$ and $S$ treatments on onion sprout biomass. The GIB reductions of broccoli and mung bean associated with the $1270 \mu \mathrm{M} \mathrm{Se}$ treatments appear to be the result of the effect of Se and not the salt. Although it was not a goal of this study to evaluate biomass changes in the presence of both $\mathrm{Se}$ and $\mathrm{S}$, future studies evaluating both elements simultaneously may enable a more complete understanding of their impact on sprout growth and production.

Some reports indicate that although germination rates of many species are unaffected by high concentrations of $\mathrm{Se}$, subsequent growth rates may be reduced (Carlson et al., 1989; Lyons et al., 2005). Existing evidence suggests the major mechanism of Se toxicity in plants is the incorporation of SeCys and SeMet into proteins in place of Cys and Met, altering the tertiary structure and catalytic activity of Sproteins (Barak and Goldman, 1997; Terry et al., 2000). Other possible mechanisms include adverse effects on the synthesis of enzymes required for chlorophyll biosynthesis and protection from oxidative stress (Terry et al., 2000). Although direct evidence is lacking, any of these mechanisms may adversely affect the tissues of the emerging radicle or other organs in germinating seeds.

These results indicate that sprouts can be grown in a fairly high $\mathrm{Se}$ concentration before yield reductions occur. It is likely that industry production of sprouts, which depends on timely growth rates and adequate yields, would be minimally affected by $\mathrm{Se}$ biofortification. For example, mung bean yield would be unaffected at $127 \mu \mathrm{M}$ Se or would need a slightly longer cultivation period if biofortified at the $635-\mu \mathrm{M}$ Se level. Sprouts may be an ideal form of fresh vegetable to achieve high level Se enrichment because at this very early stage of plant development, they may be more tolerant to the effects of Se than mature plants.

Effect of selenium treatments on selenium accumulation in sprouts. Selenium could not be detected in any of the water-treated plant samples; therefore, they were not included in the analysis. Exclusion of possible surface 
contamination was confirmed by the lack of Se detection in the last wash solution of a subsample of the sprouts (data not shown).

The effects of all of the interactions of species, treatment, and harvest date on tissue concentration of elemental Se ([Se]) were highly significant in Trial 1 and marginally significant in Trial 2 (Table 1). In Trial 1, averaged over treatments and days, onion had the highest [Se], followed by mung bean and broccoli and they all differed significantly $\left(72.5,57.8\right.$, and $40.9 \mu \mathrm{g} \cdot \mathrm{g}^{-1} \mathrm{Se}$, dry weight, respectively). In contrast, the [Se] was highest in broccoli in Trial 2 followed by mung bean and onion $\left(119.5,76.0\right.$, and $58.1 \mu \mathrm{g} \cdot \mathrm{g}^{-1}$ Se dry weight, respectively). Averaged over species and harvest dates, plants treated with $1270 \mu \mathrm{M}$ Se contained 102.2 and 140.6 $\mu \mathrm{g} \cdot \mathrm{g}^{-1}$ Se dry weight, $\approx 8.5$ and five times higher than the plants treated with $127 \mu \mathrm{M} \mathrm{Se}$ for Trials 1 and 2, respectively (12.0 and 28.3 $\mu \mathrm{g} \cdot \mathrm{g}^{-1} \mathrm{Se}$ dry weight, respectively). The [Se] of plants treated with $127 \mu \mathrm{M}$ Se did not differ significantly within species over harvest dates in both trials. The species were subsequently analyzed separately as a result of the interaction effects.

Expectedly, all species had very large treatment effects (Table 2), which were the result of the large increases in [Se] between treatments (Fig. 3). In general, large significant increases in [Se] were not found in any of the species or Se treatment levels from the first to the second harvest dates in Trial 1. This changed in Trial 2; however, only the plants in the highest Se treatment groups showed increased [Se] between dates. As a result of this and the fact that the [Se] of the second harvest date is of most interest in terms of Se delivery in the food, subsequent references to [Se] refer to the second harvest date.

The broccoli plants treated with $1270 \mu \mathrm{M}$ Se accumulated averages of 88.1 and 240.2 $\mu \mathrm{g} \cdot \mathrm{g}^{-1} \mathrm{Se}$ in Trials 1 and 2 , respectively. This was approximately six- and 2.5 -fold greater [Se] than the plants treated with $127 \mu \mathrm{M} \mathrm{Se}$ (14.4 and $96.2 \mu \mathrm{g} \cdot \mathrm{g}^{-1} \mathrm{Se}$, respectively). In Trial 2 , the $635 \mu \mathrm{M}$ Se-treated broccoli reached an intermediate level of $122.0 \mu \mathrm{g} \cdot \mathrm{g}^{-1} \mathrm{Se}$, approximately half of the concentration found in the $1270 \mu \mathrm{M}$ Se-treated plants.

In the $1270 \mu \mathrm{M}$ Se-treated mung bean plants, the [Se] reached 103.1 and 205.7 $\mu \mathrm{g} \cdot \mathrm{g}^{-1} \mathrm{Se}$ in Trials 1 and 2, respectively, approximately six- and 11-fold higher than the $127 \mu \mathrm{M}$ Se-treated plants (16.1 and 18.8 $\mu \mathrm{g} \cdot \mathrm{g}^{-1} \mathrm{Se}$, respectively). Plants treated with $635 \mu \mathrm{M}$ Se averaged $102.4 \mu \mathrm{g} \cdot \mathrm{g}^{-1}$ Se and, similar to broccoli, approximately half of the [Se] in plants treated with $1270 \mu \mathrm{M}$ Se.

Onion plants treated with $1270 \mu \mathrm{M}$ averaged $131.5 \mu \mathrm{g} \cdot \mathrm{g}^{-1} \mathrm{Se}$, almost 10 -fold more than the $127 \mu \mathrm{M}$ Se-treated plants. Onion treated with $12,700 \mu \mathrm{M}$ Se accumulated 598.7 $\mu \mathrm{g} \cdot \mathrm{g}^{-1} \mathrm{Se}$, approximately fivefold more than the $1270 \mu \mathrm{M}$ Se-treated plants.

For all of the species, the Se concentration in the plants increased with increasing Se level. Similar increases in tissue Se with increasing selenate-Se treatments have been reported for the germinating seeds of wheat,
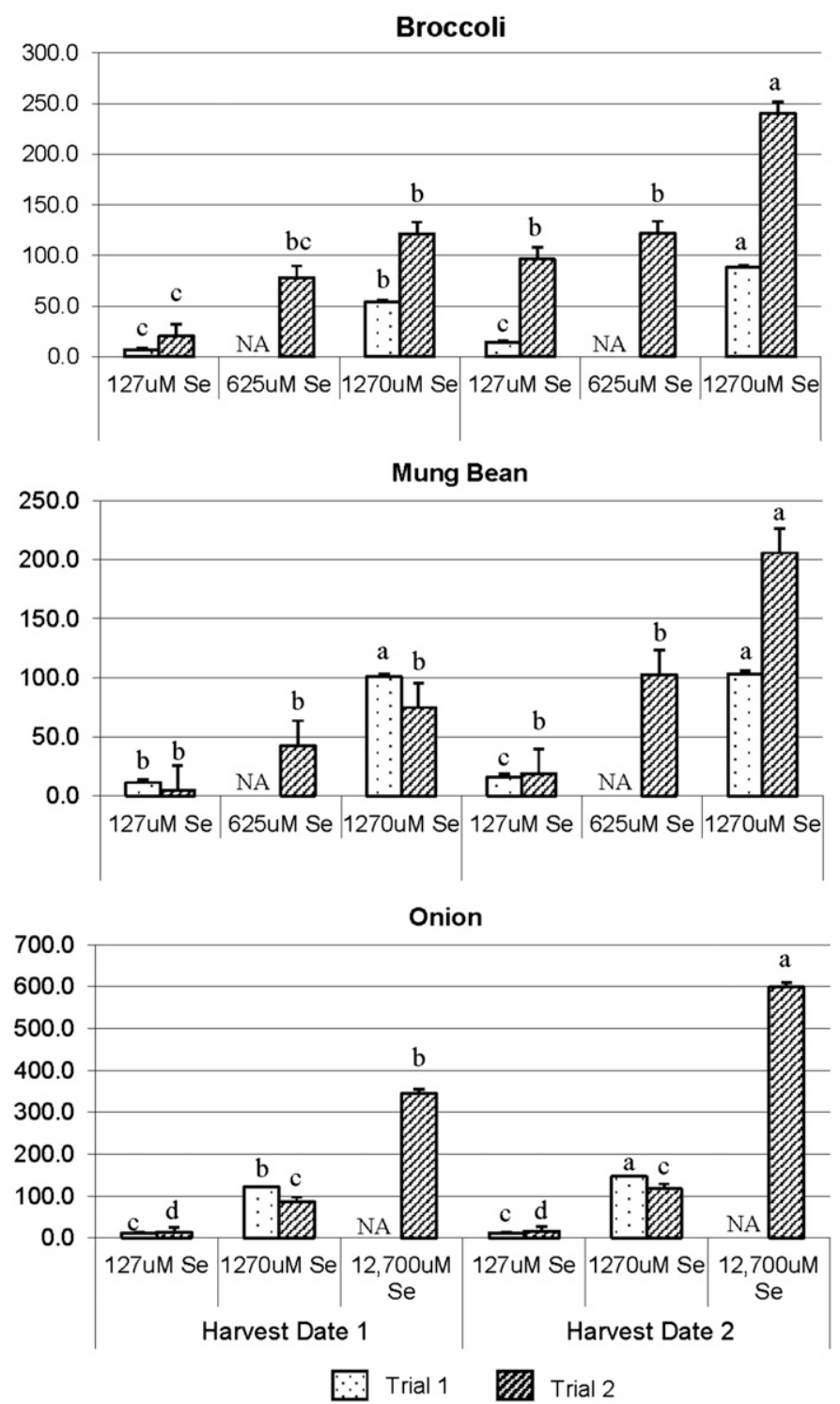

Fig. 3. Selenium concentration in plant tissue as a function of selenium treatment solution and harvest date. Bars are mean and SE of three samples. Means in the same trial with the same letter are not significantly different. Harvest 1 = Day 3 for broccoli and mung bean, Day 5 for onion; Harvest date $2=$ Day 5 for broccoli and mung bean, Day 7 for onion. NA = not applicable, treatment not used in Trial 1 .

alfalfa, and sunflower (Lintschinger et al., 2000; Lyons et al., 2005), several Brassica land races (Banuelos et al., 1997), kale (Lefsrud et al., 2006), and onion (Barak and Goldman, 1997; Kopsell and Randle, 1997). Many of these reports also demonstrated that these plants tend to accumulate Se in proportion to or greater than the amount of Se available in the soil or solution culture. Leaves from kale treated with $3.5 \mathrm{mg} \cdot \mathrm{L}^{-1} \mathrm{Se}$ as selenate accumulated as much as $1056 \mu \mathrm{g} \cdot \mathrm{g}^{-1}$ Se dry weight (Lefsrud et al., 2006). Onion leaf and bulb accumulated 208 and $70 \mu \mathrm{g} \cdot \mathrm{g}^{-1}$ Se dry weight, respectively, in response to a treatment level of $0.8 \mathrm{mg} \cdot \mathrm{L}^{-1}$ Se (Sharma et al., 2010).

The Se content of the sprouts at the second harvest date is an important value that reflects not only how the plant responds to Se supplementation, but how much Se would potentially be delivered through a food. The second harvest date of each species was chosen to represent a cultivation period in which the sprouts would be considered mature and ready for consumption. These dates were Day 5 for broccoli and mung bean and Day 7 for onion. The $127 \mu \mathrm{M} \mathrm{Se}\left(10 \mathrm{mg} \cdot \mathrm{L}^{-1}\right.$ selenateSe) -treated plants accumulated 2.3, 3.3, and $4.8 \mu \mathrm{g} \cdot \mathrm{g}^{-1} \mathrm{Se}$, fresh weight, for broccoli, mung bean, and onion, respectively, in Trial 2 . The $1270 \mu \mathrm{M}$ Se $\left(100 \mathrm{mg} \cdot \mathrm{L}^{-1}\right.$ selenate-Se $)$-treated plants accumulated $22.9,33.2$, and $62.9 \mu \mathrm{g} \cdot \mathrm{g}^{1}$ $\mathrm{Se}$, fresh weight, for broccoli, mung bean, and onion, respectively. All of these concentrations are below the level of Se in the solution. Sugihara et al. (2004), reported on the fresh weight Se content of 28 species of sprouts treated with $10 \mathrm{mg} \cdot \mathrm{L}^{-1}$ selenite-Se and found nearly all of the species to accumulate Se at concentrations greater than the environment. Broccoli and onion, cultivated for 7 and $8 \mathrm{~d}$, accumulated 32.1 and $17.8 \mu \mathrm{g} \cdot \mathrm{g}^{-1}$ Se fresh 
weight (Sugihara et al., 2004). The discrepancy may be the result of the shorter cultivation periods, different sprouting methods, or use of selenate instead of selenite in the current study.

Frias et al. (2010) determined that both good nutritional quality and low cytotoxicity could be obtained from selenite-supplemented garden cress (Lepidium sativum) sprouts; however, selenate was chosen over selenite for the current study based on several factors. Selenate uptake by roots is an active process, whereas selenite accumulates through passive diffusion. Selenite is not normally accumulated in the root and has higher toxicity in root growth (Sors et al., 2005). Additionally, the concentration of selenate in the xylem of plants is greater than the externally supplied selenate concentration, whereas the selenite concentration in the xylem of selenitesupplied plants is lower (Asher et al., 1977). However, the reason for the lower concentration of selenite in the xylem exudates may be the result of more efficient conversion of selenite to organic forms in the roots. Sharma et al. (2010) demonstrated that selenate-treated rapeseed (Brassica napus) accumulated 75160 times more Se in shoots and 2-18 times more in roots compared with selenite-treated plants at the rosette formation stage. This difference decreased at the peak flowering stage. Kahakachchi et al. (2004) found that the major Se species in selenite-treated Brassica juncea shoots were selenomethionine $(34.2 \%)$ and selenomethionine Se-oxide hydrate $(51.2 \%)$ with selenite only present in very small amounts $(4.3 \%)$. Selenate-treated plant shoots accumulated Se predominantly as selenate $(82.8 \%)$ with smaller amounts of MeSeCys (3.1\%) and SeMet (10.7\%). These data are in agreement with the findings of Sugihara et al. (2004) that Kaiware daikon sprouts grown in selenite solution contained $\mathrm{Se}$ as SeMeCys and SeMet, whereas no selenite was found. The sprouts grown with selenate retained a considerable amount of selenate as well as SeMeCys and SeMet (Sugihara et al., 2004). These authors concluded that the considerable non-metabolized selenate indicated that the reduction of selenate to selenite must be a limiting step in the selenium-metabolizing pathway and that selenite is more suitable than selenate for producing SeMeCys in sprouts. Analysis of the Se species was beyond the scope of the current study, but this would be an important step in the development of Sebiofortified foods to assure delivery of desired Se compounds.

Not only is the accumulation of various $\mathrm{Se}$ compounds influenced by the form of Se available to the plant, but Se enhancement of plants may affect the accumulation of other bioactive components. When broccoli was enriched with $800 \mu \mathrm{g} \cdot \mathrm{g}^{-1} \mathrm{Se}$, there was an $80 \%$ reduction in sulforaphane content and inhibition of the production of most phenolic acids (Finley et al., 2005). Glucosinolate levels are decreased with increasing Se concentration in rapid-cycling Brassica oleracea (Charron et al., 2001). These changes have important implications for the delivery of bioactive compounds through the diet and demonstrate the complexity of the development of functional foods.

Se-fortified foods are currently on the market, including orange juice that contains $\approx 25 \%$ of the U.S. Recommended Daily Allowance (RDA) for $\mathrm{Se}$ as sodium selenite (Tropicana Pure Premium Essentials: Immunity Defense; Tropicana Products, Inc., FL). To supply $25 \%$ of the RDA of Se as biofortified sprouts, a typical 28-g serving of sprouts would contain $\approx 13$ to $14 \mu \mathrm{g}$ Se or $0.5 \mu \mathrm{g} \cdot \mathrm{g}^{-1}$ $\mathrm{Se}$, fresh weight, well below the fresh weight [Se] of the $127 \mu \mathrm{M}$ Se-treated sprouts in both trials. Se biofortification of sprouts for fresh consumption would necessarily require $\mathrm{Se}$ application at rates below $10 \mathrm{mg} \cdot \mathrm{L}^{-1} \mathrm{Se}$ as sodium selenate using the methods used by the current study. The method of Se biofortification as well as form of Se are important and, as research previously discussed has shown, can alter not only the Se concentration, but the complement of Se species in the plant tissue. Additionally, biomass results mentioned earlier suggest that Se biofortification at application rates below $10 \mathrm{mg} \cdot \mathrm{L}^{-1} \mathrm{Se}$ would not adversely affect biomass in any of the three species tested; thus, commercial sprout production rates and yields would be comparable to nonbiofortified sprouts.

\section{Literature Cited}

Abdulah, R., A. Faried, K. Kobayashi, C. Yamazaki, E.W. Suradji, K. Ito, K. Suzuki, M. Murakami, H. Kuwano, and H. Koyama. 2009. Selenium enrichment of broccoli sprout extract increases chemosensitivity and apoptosis of $\mathrm{LNCaP}$ prostate cancer cells. BMC Cancer 9:414-426.

Asher, C.J., G.W. Butler, and P.J. Peterson. 1977. Selenium transport in root systems of tomato. J. Expt. Bot. 28:279-291.

Banuelos, G.S. 2002. Irrigation of broccoli and canola with boron- and selenium-laden effluent. J. Environ. Qual. 3:1802-1808.

Banuelos, G.S., H.A. Ajwa, L. Wu, X. Guo, S. Akohoue, and S. Zambrzuski. 1997. Seleniuminduced growth reduction in Brassica land races considered for phytoremediation. Ecotoxicol. Environ. Saf. 36:282-287.

Banuelos, G.S., Z.Q. Lin, L. Wu, and N. Terry. 2002. Phytoremediation of selenium-contaminated soils and waters: Fundamentals and future prospects. Rev. Environ. Health 17:291-306.

Barak, P. and I. Goldman. 1997. Antagonistic relationship between selenate and sulfate uptake in onion (Allium cepa): Implications for the production of organosulfur compounds in plants. J. Agr. Food Chem. 45:1290-1294.

Carlson, C.L., D.I. Kaplan, and D.C. Adriano. 1989. Effects of selenium on germination and radicle elongation of selected agronomic species. Environ. Exp. Bot. 29:493-498.

Charron, C.S., D.A. Kopsell, W.M. Randle, and C.E. Sams. 2001. Sodium selenate fertilisation increases selenium accumulation and decreases glucosinolate concentration in rapid-cycling Brassica oleracea. J. Sci. Food Agr. 81:962-966.

Ellis, D.R. and D.E. Salt. 2003. Plants, selenium and human health. Curr. Opin. Plant Biol. 6:273-279.

Fahey, J.W., Y. Zhang, and P. Talalay. 1997. Broccoli sprouts: An exceptionally rich source of inducers of enzymes that protect against chemical carcinogens. Proc. Natl. Acad. Sci. USA 94:10367-10372.

Finley, J.W., A. Sigrid-Keck, R.J. Robbins, and K.J. Hintze. 2005. Selenium enrichment of broccoli:
Interactions between selenium and secondary plant compounds. J. Nutr. 135:1236-1238.

Frias, J., P. Gulewicz, C. Martinez-Villaluenga, E. Penas, M.K. Piskula, H. Kozlowska, E. Ciska, K. Gulewicz, and C. Vidal-Valverde. 2010. Changes in nutritional value and cytotoxicity of garden cress germinated with different selenium solutions. J. Agr. Food Chem. 58:2331-2336.

Kahakachchi, C., H.T. Boakye, P.C. Uden, and J.F. Tyson. 2004. Chromatographic speciation of anionic and neutral selenium compounds in Se. J. Chromatography 52:3761-3771.

Kopsell, D.A. and W.M. Randle. 1997. Selenate concentration affects selenium and sulfur uptake and accumulation by 'Granex 33' onions. J. Amer. Soc. Hort. Sci. 122:721-726.

Kopsell, D.A. and W.M. Randle. 1999. Selenium accumulation in a rapid-cycling Brassica oleracea population responds to increasing sodium selenate concentrations. J. Plant Nutr. 22:927-937.

Lefsrud, M.G., D.A. Kopsell, D.E. Kopsell, and W.M. Randle. 2006. Kale carotenoids are unaffected by, whereas biomass production, elemental concentrations, and selenium accumulation respond to, changes in selenium fertility. J. Agr. Food Chem. 54:1764-1771.

Lemly, A.D. 2004. Aquatic selenium pollution is a global environmental safety issue. Ecotoxicol. Environ. Saf. 59:44-56.

Lintschinger, J., N. Fuchs, J. Moser, D. Kuehnelt, and W. Goessler. 2000. Selenium-enriched sprouts. A raw material for fortified cerealbased diets. J. Agr. Food Chem. 48:5362-5368.

Lyons, G.H., J.C.R. Stangoulis, and R.D. Graham. 2005. Tolerance of wheat (Triticum aestivum L.) to high soil and solution selenium levels. Plant Soil 270:179-188.

Nilsonne, G., S. Sun, C. Nystrom, A.-K. Rundlof, A. Potamitou Fernandes, M. Bjornstedt, and K. Dobra. 2006. Selenite induces apoptosis in sarcomatoid malignant mesothelioma cells through oxidative stress. Free Radic. Biol. Med. 41:862-865.

Obroucheva, N.V. and O.V. Antipova. 1997. Physiology of the initiation of seed germination. Russ. J. Plant Physiol. 44:250-264.

Sharma, S., A. Bansal, S.K. Dhillon, and K.S. Dhillon. 2010. Comparative effects of selenate and selenite on growth and biochemical composition of rapeseed (Brassica napus L.). Plant Soil 329:339-348.

Sors, T.G., D.R. Ellis, and D.E. Salt. 2005. Selenium uptake, translocation, assimilation and metabolic fate in plants. Photosynth. Res. 86: 373-389.

Sugihara, S., M. Kondo, Y. Chihara, M. Yuji, H. Hattori, and M. Yoshida. 2004. Preparation of selenium-enriched sprouts and identification of their selenium species by high-performance liquid chromatography-inductively coupled plasma mass spectrometry. Biosci. Biotechnol. Biochem. 68:193-199.

Terry, N., A. Zayed, M. de Souza, and A. Tarun. 2000. Selenium in higher plants. Annu. Rev. Plant Physiol. 51:401-432.

Tsavachidou, D., T.J. McDonnell, S. Wen, X. Wang, F. Vakar-Lopez, L.L. Pisters, C.A. Pettaway, C.G. Wood, K.A. Do, P.F. Thall, C. Stephens, E. Efstathiou, R. Taylor, D.G. Menter, P. Troncoso, S.M. Lippman, C.J. Logothetis, and J. Kim. 2009. Selenium and vitamin E: Cell type- and intervention-specific tissue effects in prostate cancer. J. Mat. Cancer Inst. 101:306-320.

USEPAUSEPA 3050B, Method 3050B. Acid digestion of sediments, sludges and soils. 10 Jan. 2012. $<$ http://www.epa.gov/waste/hazard/testmethods/ sw846/ pdfs/3050b.pdf $>$. 